\title{
Oxidative Stress in Critically Ill Children with Sepsis
}

\author{
Derek S. Wheeler*
} Division of Critical Care Medicine, Cincinnati Children's Hospital Medical Center; The Kindervelt Laboratory for
Critical Care Medicine Research, Cincinnati Children's Research Foundation; Clinical Pediatrics, University of
Cincinnati College of Medicine, USA

\begin{abstract}
Sepsis is one of the leading causes of death in critically ill patients in the intensive care unit. Sepsis accounts for significant morbidity and mortality in critically ill children as well. The pathophysiology of sepsis is characterized by a complex systemic inflammatory response, endothelial dysfunction, and alterations in the coagulation system, which lead to perturbations in the delivery of oxygen and metabolic substrates to the tissues, end-organ dysfunction, and ultimately death. Oxidative stress plays a crucial role as both a promoter and mediator of the systemic inflammatory response, suggesting potential targets for the treatment of critically ill children with the sepsis syndrome. Herein, we will provide a brief review of the role of oxidative and nitrosative stress in the pathophysiology of sepsis.
\end{abstract}

Keywords: Oxidative stress, nitrosative stress, free radicals, oxygen radicals, nitric oxide, sepsis, shock, critical illness.

\section{INTRODUCTION}

Sepsis is a leading cause of morbidity and mortality in children and accounts for nearly 4,500 deaths and close to $\$ 2$ billion per year in healthcare expenditures in the United States alone [1]. The pathophysiology of sepsis is characterized by a complex systemic inflammatory response, endothelial dysfunction, and alterations in the coagulation system, which lead to perturbations in the delivery of oxygen and metabolic substrates to the tissues, end-organ dysfunction, and ultimately death. Importantly, therapy directed at restoring oxygen and substrate delivery to the tissues has been shown to improve outcome [2]. Oxidative stress plays a crucial role as both a promoter and mediator of the systemic inflammatory response, suggesting potential targets for the treatment of critically ill children with the sepsis syndrome [3-7]. Herein, we will provide a brief review of the role of oxidative and nitrosative stress in the pathophysiology of sepsis.

\section{THE OXYGEN PARADOX}

Oxygen is the most abundant element in the earth's crust, and cellular function is critically dependent upon oxygen, as evidenced by the relative complexity of the three major organ systems that have evolved to transport oxygen from the surrounding environment to the cells - namely, the cardiovascular, respiratory, and hematopoeitic systems. Cells do not have the means to store oxygen and are therefore dependent upon a continuous supply that closely matches the changing metabolic needs that are necessary for normal metabolism and cellular function. The terms hypoxia and hypoxemia are frequently (and probably incorrectly) used

\footnotetext{
*Address correspondence to this author at the Division of Critical Care Medicine, Cincinnati Children's Hospital Medical Center, 3333 Burnet Avenue, Cincinnati, OH 45229-3039, USA;

Tel: (513) 636-4259; Fax: (513) 636-4267;

E-mail: Derek.wheeler@cchmc.org
}

interchangeably. A more purist approach would be to define hypoxia as a lower than normal partial pressure of oxygen $\left(\mathrm{PO}_{2}\right)$ in the tissues. Hypoxemia is then defined as a lower than normal partial pressure of oxygen in the blood $\left(\mathrm{PaO}_{2}\right)$. There are a few well-known types of hypoxia: (i) Hypoxemic hypoxia (due to lower than normal $\mathrm{PaO}_{2}$ ); (ii) Anemic hypoxia (due to decreased oxygen carrying capacity of the blood, due to either a low red blood cell count or the presence of abnormal hemoglobin); (iii) Circulatory hypoxia (also known as stagnant hypoxia, due to lower than normal cardiac output); and (iv) Histotoxic hypoxia (due to cyanide poisoning or "poisoning" due to sepsis - see discussion on cytopathic hypoxia below). Note that if the supply of oxygen is not aligned with the normal metabolic requirements of the tissues, for whatever reason, tissue hypoxia will ensue, eventually resulting in cellular injury and/or death. Ironically, oxygen is inherently toxic to these same cells that are so critically dependent upon a steady supply of oxygen for normal cellular function - the so-called oxygen paradox [8-11]. Exposure to hyperoxia in vivo results in direct damage to the lung through the increased production of free radicals and indirect damage from the accumulation of proinflammatory mediators, frequently resulting in death within 24-48 hours of exposure in rodent models [12, 14]. Physiologic studies conducted in healthy volunteers breathing $100 \%$ oxygen confirmed the toxic effects of oxygen as early as the 1940's [15].

The toxicity of oxygen rests in its unique atomic structure. Each oxygen atom contains one unpaired electron in its outer orbit. Elemental oxygen is therefore considered a free radical (Table 1). However, oxygen exists in the atmosphere as $\mathrm{O}_{2}$, and hence contains two unpaired electrons with parallel spins. During normal cellular respiration, oxygen is reduced to $\mathrm{H}_{2} \mathrm{O}$ through the sequential addition of 4 electrons at the inner membrane of the mitochondria, thereby generating the necessary chemical energy to generate 36 molecules of adenosine triphosphate (ATP). Nearly $98 \%$ 
Table 1. Definition of Terms

\section{Free radicals}

Any atom or molecule containing one or more unpaired electrons in the outermost orbit or electron shell. By convention, the unpaired electron is represented as a bold superscripted dot (e.g. $\mathrm{O}_{2}^{-}$).

\section{$\underline{\text { Redox }}$}

Any chemical reaction in which an atom has its oxidation state changed (short-hand notation for reduction-oxidation reaction)

\section{Oxidation state}

A measure of the degree of oxidation of an atom in any substance, defined as the charge an atom might be expected to have if all bonds to atoms of different elements were $100 \%$ ionic

Example: Ferrous iron (Fe-II) has an oxidation state of +2 , while ferric iron $(\mathrm{Fe}-\mathrm{III})$ has an oxidation state of +3

\section{Oxidation}

The loss of electrons in a chemical reaction (i.e. an increase in the oxidation state)

\section{Reduction}

The gain of electrons in a chemical reaction (i.e. a decrease in the oxidation state)

\section{Reducing agent}

The atom or molecule in a redox reaction that reduces another species (and in so doing, becomes oxidized); the electron donor in a redox reaction

\section{Oxidizing agent}

The atom or molecule in a redox reaction that oxidizes another species (and in so doing, becomes reduced); the electron acceptor in a redox reaction

\section{Reactive oxygen species}

Molecules or atoms formed by the reduction of oxygen

\section{Oxidative stress}

An imbalance or disequilibrium between pro-oxidant and anti-oxidant activity

of oxygen is converted to water in this manner. The remaining $2 \%$ of oxygen undergoes partial and incomplete reduction due to the leakage of electrons across the respiratory chain, resulting in the formation of intermediate reactive oxygen species (ROS) - namely, superoxide $\left(\mathrm{O}_{2}{ }^{-}{ }^{-}\right)$, hydrogen peroxide $\left(\mathrm{H}_{2} \mathrm{O}_{2}\right)$, and the hydroxyl radical $\left(\mathrm{OH}^{\circ}\right)$.

\section{GENERATION OF REACTIVE OXYGEN SPECIES (ROS)}

Under normal physiologic conditions, the principal source of ROS is the incomplete reduction of $\mathrm{O}_{2}$ as a normal byproduct of aerobic respiration. One or two electron reduction of oxygen forms two ROS, superoxide anion $\left(\mathrm{O}_{2}{ }^{--}\right)$ and hydrogen peroxide $\left(\mathrm{H}_{2} \mathrm{O}_{2}\right)$, respectively, which can then be converted into more reactive species, such as the hydroxyl radical. The superoxide anion is formed after the addition of one electron to oxygen and is generally the least reactive ROS. It is rapidly inactivated by the anti-oxidant enzyme, superoxide dismutase (SOD), which reduces it to hydrogen peroxide (Eq. 1).

$2 \mathrm{O}_{2}{ }^{\cdot-}+2 \mathrm{H}^{+} \rightarrow \mathrm{H}_{2} \mathrm{O}_{2}+\mathrm{O}_{2}$

Hydrogen peroxide is much less reactive and is converted enzymatically to water by catalase (Eq. 2) and glutathione peroxidase (which requires glutathione, GSH and produces glutathione disulfide, GSSG and water) (Eq. 3).

$$
\begin{aligned}
& 2 \mathrm{H}_{2} \mathrm{O}_{2} \rightarrow \mathrm{O}_{2}+\mathrm{H}_{2} \mathrm{O} \\
& \mathrm{H}_{2} \mathrm{O}_{2}+2 \mathrm{GSH} \rightarrow \text { GSSG }+2 \mathrm{H}_{2} \mathrm{O}
\end{aligned}
$$

In the presence of transition metals (e.g. copper, iron), the Haber-Weiss reaction generates the highly reactive hydroxyl radical $\left(\mathrm{OH}^{-}\right)$and the hydroxyl anion $\left(\mathrm{OH}^{-}\right)$from hydrogen peroxide and the superoxide anion. The first step of this reaction involves reduction of the transition metal (reduction of ferric iron to ferrous iron is shown) (Eq. 4). The second step of this reaction is known as the Fenton reaction (Eq. 5).

$\mathrm{Fe}^{3+}+\mathrm{O}_{2}{ }^{--} \rightarrow \mathrm{Fe}^{2+}+\mathrm{O}_{2}$

$\mathrm{Fe}^{2+}+\mathrm{H}_{2} \mathrm{O}_{2} \rightarrow \mathrm{Fe}^{3+}+\mathrm{OH}^{\cdot}+\mathrm{OH}^{-}$

The net reaction is shown in Eq. 6.

$\mathrm{O}_{2}{ }^{\cdot-}+\mathrm{H}_{2} \mathrm{O}_{2} \rightarrow \mathrm{OH}^{-}+\mathrm{OH}^{-}+\mathrm{O}_{2}$

The hydroxyl radical in turn causes damage to proteins, lipids, and nucleic acids. Hydroxyl radicals oxidizes amino acids such as lysine, serine, arginine, and proline to inactivate cellular proteins. Hydroxyl radical removes hydrogen from membrane lipids, generating a lipid radical that can then react with oxygen to generate a peroxy radical. The peroxy radical in turn removes another hydrogen from the next membrane lipid to initiate a chain reaction known as lipid peroxidation. Finally, hydroxyl radical causes base modification, strand breaks, and cross-linking in nucleic acids.

Other major sources of ROS under normal conditions include the respiratory burst during phagocytosis (largely due to the effects of a multi-component enzyme complex, NADPH oxidase) (Eq. 7) and arachidonic acid metabolism [16].

$\mathrm{NADPH}+\mathrm{H}^{+}+2 \mathrm{O}_{2} \rightarrow \mathrm{NADP}^{+}+2 \mathrm{H}^{+}+2 \mathrm{O}_{2}{ }^{-}$

The NADPH required for this reaction is generated through the hexose monophosphate shunt (HMP shunt) - an alternative biochemical pathway starting from glucose-6phosphate which primarily generates NADPH for reductive synthesis and ribose sugars for nucleic acid synthesis. The 
respiratory burst is a major source of ROS, especially during stress (e.g. sepsis, shock, and ischemia-reperfusion injury).

Other enzyme systems also generate significant ROS species. For example, the xanthine oxidoreductase (XOR) enzyme system is a key enzyme in purine catabolism and catalyzes the oxidation of xanthine and hypoxanthine to uric acid. XOR is primarily localized to the vascular endothelium and smooth muscle cells and exists in two interconvertible forms - xanthine dehydrogenase (XDH) and xanthine oxidase $(\mathrm{XO})$. $\mathrm{XDH}$ is irreversibly converted to $\mathrm{XOR}$ via proteolysis or reversibly by oxidation of cysteine residues to form disulfide bridges. $\mathrm{XDH}$ uses $\mathrm{NAD}^{+}$as the electron acceptor, while $\mathrm{XO}$ uses $\mathrm{O}_{2}$ as the electron acceptor (generating superoxide anion in the process) (Fig. 1). During tissue ischemia, $\mathrm{XDH}$ is converted to the oxidase form by a protease activated by increased calcium flux. At the same time, ATP is degraded to hypoxanthine, which accumulates in the ischemic tissue. During reperfusion, with the presence of large quantities of molecular oxygen and high concentrations of hypoxanthine, XO generates a burst of superoxide. Recently, the XOR enzyme system has been shown to catalyze the reduction of nitrates and nitrites to nitrites and $\mathrm{NO}^{\circ}$, respectively, thus also contributing to $\mathrm{NO}^{\circ}$ generation during ischemia-reperfusion injury $[17,18]$.

\section{ANTI-OXIDANT DEFENSE MECHANISMS}

The evolution of highly efficient mechanisms of energy production via aerobic respiration coincided in parallel with the evolution of a complex network of anti-oxidant defense mechanisms necessary to combat the generation of ROS as a byproduct of this same energy-producing process. Generally, under normal physiologic conditions, the balance between ROS production and elimination is maintained by the components of anti-oxidant defense. Some of the most important components of this anti-oxidant defense include the anti-oxidant enzymes discussed above that rapidly eliminate toxic ROS intermediates generated during normal metabolism. These enzymes include superoxide dismutase
(SOD), catalase, and glutathione peroxidase. Three major forms of SOD are recognized - copper-zinc SOD $(\mathrm{Cu}, \mathrm{Zn}$ SOD), largely confined to the cytosol; manganese SOD (MnSOD), largely confined to the mitochondria; and extracellular SOD, largely confined to the extracellular matrix. As mentioned above, SOD generates hydrogen peroxide, which is subsequently converted to water by the enzymes, catalase and glutathione peroxidase. Additional enzymes important for anti-oxidant defense include the thioredoxin system (Fig. 2), which reduces oxidized cysteine groups on proteins and scavenges $\mathrm{H}_{2} \mathrm{O}_{2}$, glutathione reductase (Eq. 8), glutathione-S-transferase (important in detoxification and drug metabolism), and heme oxygenase (Eq. 9).

$$
\begin{aligned}
& \mathrm{GSSG}+\mathrm{NADPH}+\mathrm{H}^{+} \rightarrow 2 \mathrm{GSH}+\mathrm{NADP}^{+} \\
& \text {Heme }+\mathrm{O}_{2} \rightarrow \text { Biliverdin }+\mathrm{Fe}^{2+}+\mathrm{CO}
\end{aligned}
$$

Heme oxygenase $(\mathrm{HO})$ exists as an inducible isoform (HO-1), as well as two constitutive isoforms (HO-2 and -3). A broad spectrum of cell stressors, including LPS, phorbol esters, sodium arsenite, hydrogen peroxide, ultraviolet radiation, hyperoxia, heavy metals, and heat shock can induce HO-1 expression, which has led to its classification as a heat shock protein (Hsp32) [19]. Heme oxygenase generates biliverdin, which is converted to bilirubin (itself, a potent endogenous anti-oxidant) via biliverdin reductase. Carbon monoxide (CO) has recently gained interest as unique cell signaling molecule with anti-inflammatory and anti-apoptotic effects [20].

Superoxide and hydrogen peroxide are converted to the highly reactive hydroxyl radical in the presence of transition metals (e.g., iron, copper) via the Haber-Weiss and Fenton reactions. Several plasma proteins, including transferrin, ferritin, lactoferrin, and ceruloplasmin bind these transition metals and prevent this reaction. Haptoglobin binds free hemoglobin (which is pro-oxidant by virtue of the fact that it may be degraded to free iron and has been shown to directly stimulate lipid peroxidation). Albumin, one of the most

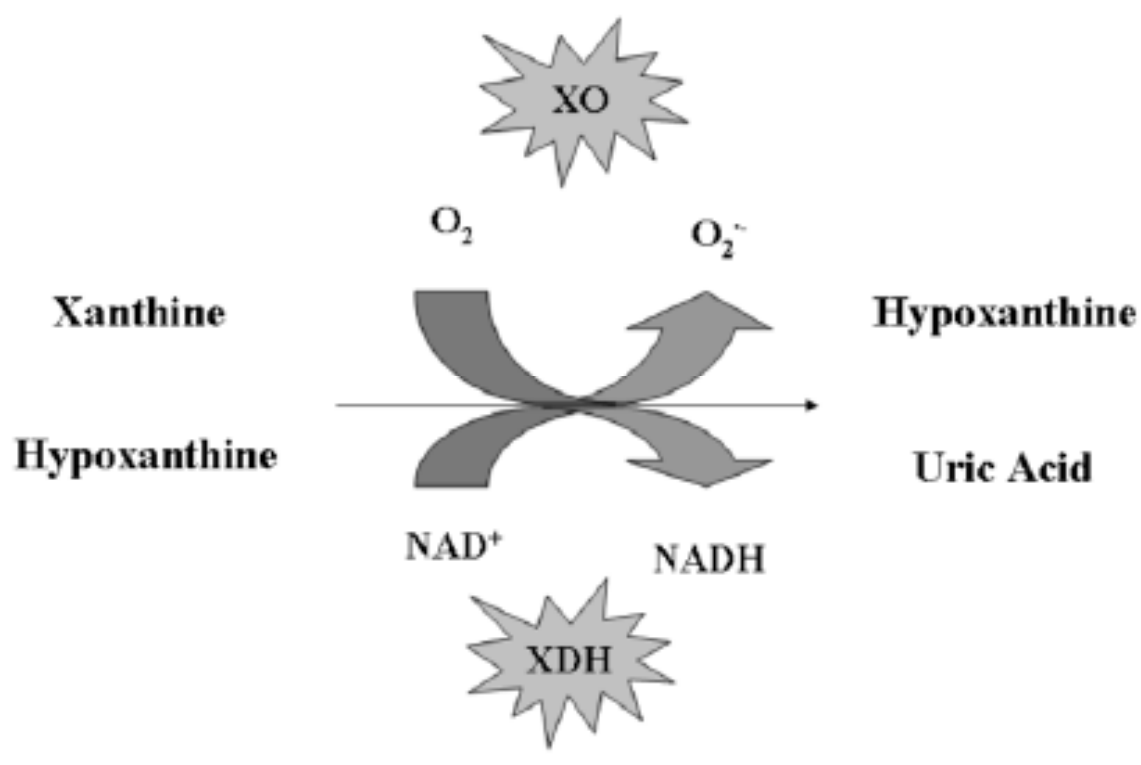

Fig. (1). Purine catabolism by the xanthine oxidoreductase (XOR) enzyme system. 


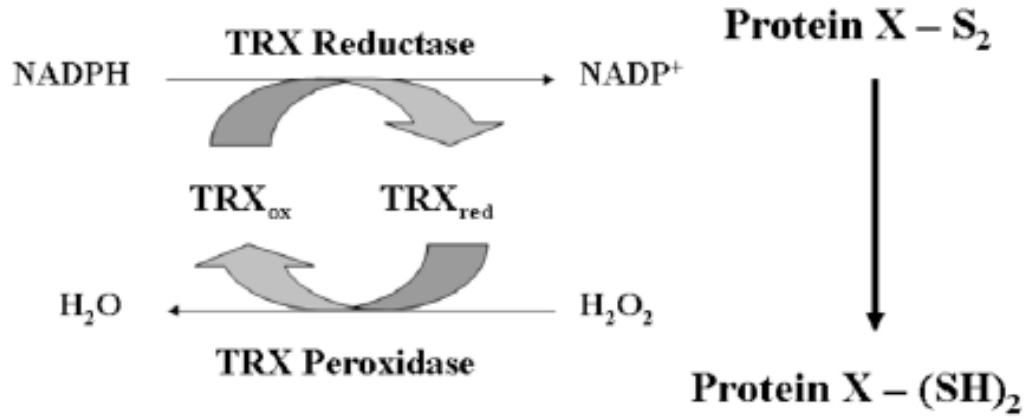

Fig. (2). Regulation of Redox Status in the Cell by the Thioredoxin (TRX) System.

abundant proteins in plasma, is an effective scavenger of free radicals. Finally, small molecules such as bilirubin (generated by heme oxygenase, above), uric acid, ubiquinone (coenzyme Q), metallothionein, and glutathione also contribute to the plasma anti-oxidant pool.

Several micronutrients are effective anti-oxidants. As alluded to above, polyunsaturated lipids in the cell membrane are particularly vulnerable to oxidative stress via lipid peroxidation. Vitamin E ( $\alpha$-tocopherol) is a lipidsoluble anti-oxidant that can interrupt the chain reaction that leads to lipid peroxidation to form the stable $\alpha$-tocopheryl radical, which is recycled by either vitamin $\mathrm{C}$ (ascorbic acid) or by ubiquinone (coenzyme Q). $\beta$-carotene and other carotenoids (e.g. lycopene) are important dietary antioxidants. $\beta$-carotene is a precursor for vitamin $\mathrm{A}$, another important anti-oxidant. Both vitamin $\mathrm{A}$ and $\mathrm{C}$ are cofactors for several enzymes and appear to directly scavenge free radicals. Finally, several minerals are important co-factors for the anti-oxidant enzymes discussed above, including selenium (glutathione peroxidase), copper (SOD, catalase), zinc (SOD), and manganese (SOD).

\section{GENERATION OF REACTIVE NITROGEN SPECIES (RNS)}

Reactive species can be nitrogen-centered as well. The primary source of reactive nitrogen species (RNS) in most biological systems is the free radical, nitric oxide (NO'). NO plays a critical role in a number of normal physiologic processes, including neurotransmission, regulation of vascular tone, and host defense. $\mathrm{NO}^{\circ}$ in mammalian tissues is synthesized by three distinct isoforms of the enzyme, nitric oxide synthase (NOS), which catalyzes the conversion of Larginine to L-citrulline and NO. A fourth isoform, mitochondrial NOS (mtNOS) has also been described [2123]. NOS1 (also known as neuronal NOS, nNOS) and NOS3 (also known as endothelial NOS, eNOS) are constitutively expressed and are activated by reversible binding of $\mathrm{Ca}^{2+} /$ calmodulin following elevations in intracellular $\mathrm{Ca}^{2+}$. NOS1 is found primarily in the kidney, muscle, myocardium, and pancreas and plays an important role as a neurotransmitter. NOS3 is largely confined to the vascular endothelium and plays a major role in the regional regulation of vascular tone and blood flow. Consistent with their role in cell signaling and regulation of vascular tone, the constitutive isoforms produce $\mathrm{NO}^{\circ}$ in nanomolar concentrations for a very short half-life.
In contrast, NOS2 (also known as inducible NOS, iNOS) is expressed in vascular smooth muscle, immune cells, erythrocytes, kidney, pancreas, liver and lung and produces longer lasting $\mathrm{NO}^{\circ}$ in micromolar concentrations. NOS2 gene expression is highly inducible in response to a variety of proinflammatory stimuli, including lipopolysaccharide (LPS), tumor necrosis factor (TNF)- $\alpha$, and interleukin (IL)- $1 \beta$. Excessive $\mathrm{NO}^{\circ}$ production by NOS2 is thought to play a major role in the pathophysiology of septic shock [24]. The source of this excessive $\mathrm{NO}^{\circ}$ production appears to be parenchymal cells, and not leukocytes as previously believed $[25,26]$. While several pre-clinical studies of NO inhibition have shown promise [27], a recent phase III multi-center, randomized, placebo-controlled trial of the NOS inhibitor 546C88 in critically ill patients with septic shock was stopped prematurely due to an increase in mortality in patients who were randomized to the treatment group [28]. As expected, there was a significant increase in blood pressure, a significant decrease in vasopressor requirements, and a significant increase in resolution of shock in the patients randomized to the treatment group. Therefore, it appears that $\mathrm{NO}^{\circ}$ has dual effects - both protective and deleterious - in patients with septic shock [24].

As alluded to earlier, $\mathrm{NO}^{\circ}$ has a relatively short half-life and rapidly degrades to nitrite $\left(\mathrm{NO}_{2}{ }^{-}\right)$and nitrate $\left(\mathrm{NO}_{3}{ }^{-}\right)$in vivo. For this reason, $\mathrm{NO}^{-}$is difficult to measure and hence $\mathrm{NO}_{2}^{-}$and $\mathrm{NO}_{3}^{-}$(often abbreviated as $\mathrm{NO}_{\mathrm{x}}$ ) are used as surrogates of $\mathrm{NO}^{\circ}$ production in most clinical studies [2933]. Recent studies suggest, however, that nitrite, in particular, may serve as an important storage pool for NO. Nitrite is reduced back to $\mathrm{NO}^{\circ}$ (in part, by XOR) under conditions of hypoxia or acidosis, causing local vasodilation to increase local tissue oxygen delivery [34].

The reaction of $\mathrm{NO}^{-}$with the superoxide anion $\left(\mathrm{O}_{2}^{-}\right)$is perhaps more relevant to the present discussion, as peroxynitrite $\left(\mathrm{ONOO}^{-}\right)$is a highly reactive $\mathrm{RNS}$ which directly damages cellular proteins, membrane lipids, and nucleic acids (Eq. 10) [35, 36].

$\mathrm{NO}+\mathrm{O}_{2}^{-} \rightarrow \mathrm{ONOO}^{-}$

Most of the adverse effects of RNS appear to be mediated by the peroxynitrite radical and are discussed further below.

\section{OXIDATIVE AND NITROSATIVE STRESS IN SEPSIS}

Oxidative stress is results from an imbalance between ROS/RNS generation and the body's anti-oxidant defenses, 
Table 2. Relevant Biomarkers of Oxidative Stress

\begin{tabular}{|c|c|c|}
\hline Serum or Plasma & Urine & Exhaled Breath Condensate \\
\hline \hline Glutathione (GSH/GSSG) & F2-isoprostanes & Hydrogen peroxide \\
\hline F2-isoprostanes & TBARS ${ }^{*}$ & TBARS $^{*}$ \\
\hline Protein carbonyls & 8-Oxo-7,8-dihydro-2deoxyguanosine \\
\hline Malondialdehyde (MDA) & & \\
\hline Lipid peroxides & & \\
\hline
\end{tabular}

"Thiobarbituric acid-reacting substances.

due to (i) increased generation of ROS/RNS; (ii) decreased synthesis or consumption of the body's natural antioxidants; or (iii) a combination of both processes. Oxidative stress is quantified in vivo via a number of methods (Table 2) [3739]. Alternatively, levels of anti-oxidants (e.g., $\alpha$-tocopherol, $\beta$-carotene, selenium, ascorbic acid) or the activities of relevant anti-oxidant enzymes (e.g. superoxide dismutase, catalase, glutathione) may be measured. Unfortunately, very few studies have measured biomarkers of oxidative stress in critically ill children with sepsis (Table 3) [40]. However, absence of evidence does not necessarily mean absence of effect! The multitude of pre-clinical studies and studies in critically ill adults strongly implicate oxidative stress in the pathophysiology of sepsis [4].

Importantly, both ROS and RNS contribute to the host inflammatory response either via direct cellular toxicity or through the activation of pro-inflammatory gene expression pathways (Fig. 3). ROS and RNS have direct effects (via oxidation or nitration reactions, respectively) on the structure and function of many enzymes, proteins, lipids, and DNA. These effects disrupt the function of the machinery of the cell - proteins! Critical enzymes, transcription factors, and scaffolding proteins are rendered non-functional through these modifications. As discussed previously, lipid peroxida- tion results in disruption of the cell membrane as well as the membranes of cellular organelles, and causes the release of highly cytotoxic products, including malondialdehyde. The release of these contents, which may include endogenous danger signals such as heat shock proteins or HMGB-1 may further activate the inflammatory response in surrounding cells $[41,42]$.

ROS interaction with nucleic acids results in the production of markers of oxidative stress, such as 8hydroxydeoxyguanosine and 8-nitroguanine. In addition, ROS induces single strand breaks in the DNA, which subsequently activates a putative nuclear repair enzyme, known as poly (ADP-ribose) polymerase-1 (PARP-1). PARP-1 (also called PARS, poly (ADP-ribose) synthetase) is a nuclear enzyme activated by single strand breaks and nicks in DNA and can therefore be induced by a diverse range of environmental stimuli, including ROS and RNS. PARP-1 is composed of three functional domains - an N-terminal DNA binding domain that binds to single strand DNA breaks, a central automodification domain, and a C-terminal catalytic domain. Once activated, PARP-1 binds to the break in DNA, activating the C-terminal catalytic domain which then cleaves $\mathrm{NAD}^{+}$into nicotinamide and ADP-ribose. PARP-1 then covalently attaches ADP-ribose groups to other proteins

Table 3. Oxidative Stress in Critically ill Children with Sepsis

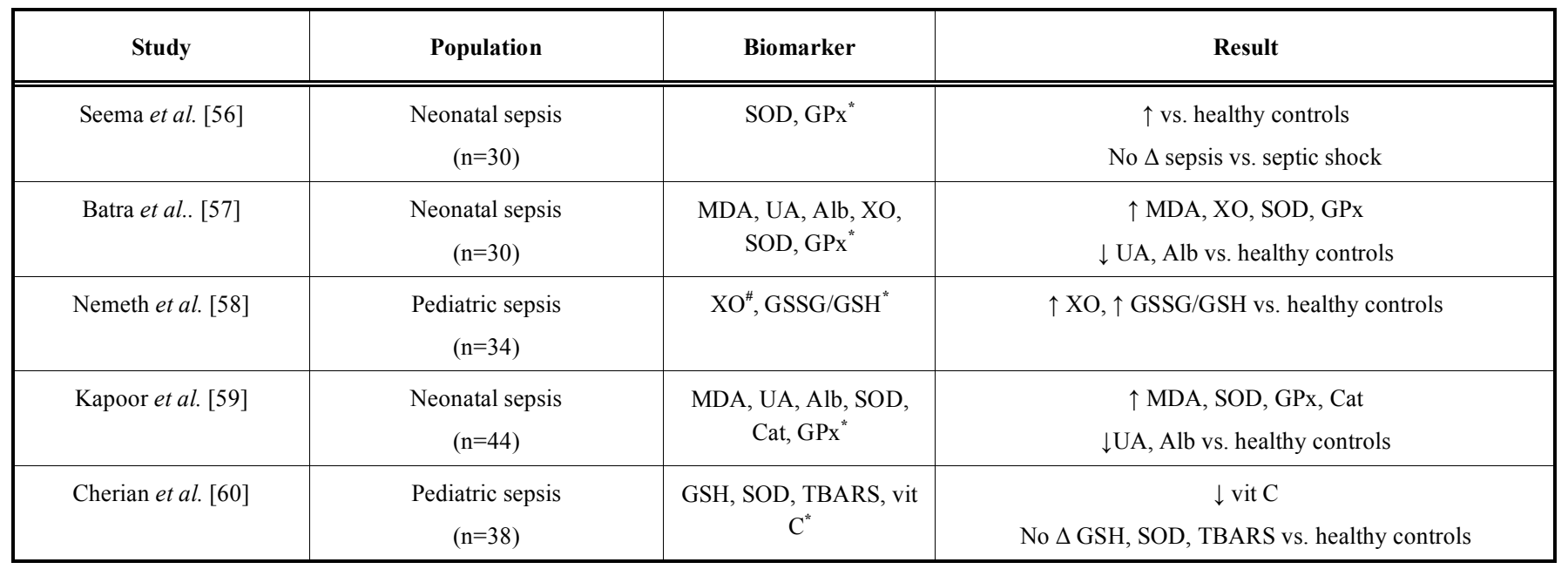

Note: SOD (superoxide dismutase), GPx (Glutathione peroxidase), MDA (malondialdehyde), UA (uric acid), Alb (albumin), XO (xanthine oxidase), GSSG/GSH (ratio between oxidized and reduced glutathione ), Cat (catalase), TBARS (thiobarbituric acid-reacting substances), vit C (Vitamin C)

*Samples obtained from serum or plasma

\#Samples obtained from urine. 


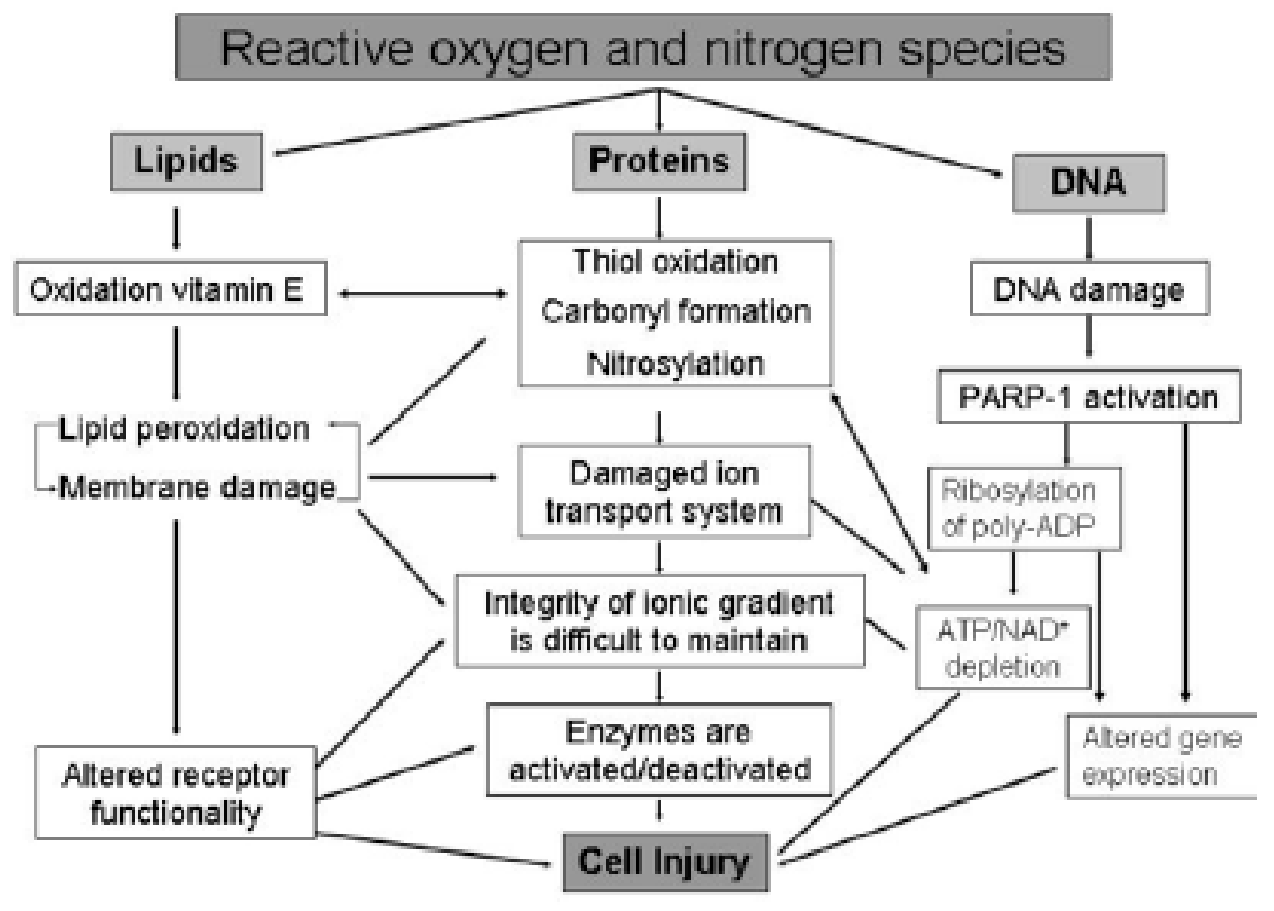

Fig. (3). The toxic effects of ROS/RNS.

(including the automodification domain on PARP-1 itself), culminating in the extension of a nucleic acid-like polymer, poly (ADP)-ribose. Unfortunately, PARP-1 also initiates an energy consuming cycle, which rapidly depletes the intracellular $\mathrm{NAD}^{+}$and ATP pools, slowing the rate of cellular respiration to the point where the cell more or less commits suicide [43]. This cell suicide phenomenon has been suggested to form the basis for a condition known as cytopathic hypoxia that characterizes sepsis and multiple organ dysfunction syndrome (MODS) [44].

ROS and RNS species also appear to cause indirect tissue damage via activation of pro-inflammatory transcription pathways that regulate pro-inflammatory gene expression. These reactive species appear to cause changes in critical thiol groups or aminoacid residues of mitogen-activated protein kinases and their regulatory phosphatases, which are important components of an extensive network of interconnected signal transduction pathways. Mitogenactivated protein kinases mediate the transduction of extracellular signals from the receptor levels to the nuclear transcription factors, such as AP-1 and NF- $\mathrm{BB}$. These kinases activate each other by sequential steps of phosphorylation; whereas their inactivation is mediated by phosphatases through dephosphorylation. NF- $\mathrm{kB}$ appears to be a master switch, or control point, for the expression of a large number of proinflammatory genes (Table 4).

NF- $\kappa \mathrm{B}$ and AP-1 appear to be regulated by the redox status inside the cell. Interestingly, intracellular redox status appears to have opposing roles on these two pluripotent transcription factors. In general, pro-oxidant factors activate $\mathrm{NF}-\kappa \mathrm{B}$ and attenuate AP-1, while anti-oxidant factors activate AP-1 and attenuate NF- $\mathrm{KB}$ [45]. A large body of indirect and direct evidence links the NF- $\mathrm{KB}$ pathway to the dysregulated inflammation that is characteristic of septic shock [46-49]. Based upon these studies, the NF- $\mathrm{B}$ pathway would appear to be a logical therapeutic target for the treatment of critically ill patients with septic shock, perhaps through modification of redox status [48].

Table 4. Genes Regulated by the Transcription Factor, NF-KB

\section{Cytokines and Chemokines}

Tumor necrosis factor- $\alpha$

Interleukins-1, $-2,-3,-6,-8$, and -12

RANTES

Eotaxin

Gro- $\alpha,-\beta$, and $-\gamma$

Macrophage inhibitory protein 1alpha (MIP-1 $\alpha$ )

Macrophage chemotactic protein 1 (MCP-1)

\section{Cell Adhesion Molecules}

Intracellular adhesion molecule 1 (ICAM-1)

Vascular cell adhesion molecule 1 (VCAM-1)

E-selectin

\section{Growth Factors}

Granulocyte-macrophage colony-stimulating factor (GM-CSF)

Granulocyte colony-stimulating factor (G-CSF)

Macrophage colony-stimulating factor (M-CSF)

\section{Miscellaneous}

Inducible Nitric oxide synthase

$\mathrm{C}$ reactive protein (CRP)

5-lipoxygenase

Inducible cyclo-oxygenase 2 


\section{NOVEL THERAPEUTIC AGENTS DIRECTED AGAINST OXIDATIVE STRESS - A RATIONAL AP- PROACH?}

Several novel therapeutic agents directed towards the oxidative stress response have shown promising results in pre-clinical models of sepsis. Unfortunately, there have been relatively few successes in the clinical setting $[4,39,50,51]$ and the experience with these agents in the pediatric population is quite limited [52]. This particular problem is not new. Promising therapies in pre-clinical models of sepsis have universally failed to live up to initial expectations in subsequent clinical trials [53]. In fact, to date, there have been only two positive clinical trials in critically ill adults with sepsis - early goal-directed therapy (EGDT) [2] and activated protein $C$ (drotrecogin alfa, Xigris ${ }^{\circledR}$, Eli Lilly and Co, Indianapolis, IN) [54]. Regardless, this kind of management approach seems both reasonable and feasible [55], though further studies, particularly in critically ill children, are required.

\section{ACKNOWLEDGEMENT}

Supported by the National Institutes of Health, K08GM077432 (DSW), R03HD058246 (DSW).

\section{REFERENCES}

[1] Watson RS, Carcillo JA, Linde-Zwirble WT, Clermont G, Lidicker J, Angus DC. The epidemiology of severe sepsis in children in the United States. Am J Respir Crit Care Med 2003; 167: 695-701.

[2] Rivers E, Nguyen B, Havstad S, et al. Early goal-directed therapy in the treatment of severe sepsis and septic shock. N Engl J Med 2001; 345: 1368-77.

[3] Taylor DE, Piantadosi CA. Oxidative metabolism in sepsis and sepsis syndrome. J Crit Care 1995; 10: 122-35.

[4] Crimi E, Sica V, Williams-Ignarro S, et al. The role of oxidative stress in adult critical care. Free Radic Biol Med 2006; 40: 398406.

[5] Crimi E, Sica V, Slutsky AS, et al. Role of oxidative stress in experimental sepsis and multisystem organ dysfunction. Free Radic Res 2006; 40: 665-72.

[6] Biswal S, Remick DG. Sepsis: redox mechanisms and therapeutic opportunities. Antioxid Redox Signal 2007; 9: 1959-61.

[7] von Dessauer B, Bongain J, Molina V, Quilodran J, Castillo R, Rodrigo R. Oxidative stress as a novel target in pediatric sepsis management. J Crit Care 2010; [Epub ahead of print].

[8] Davies KJ. Oxidative stress - the paradox of aerobic life. Biochem Soc Symp 1995; 61: 1-31.

[9] Latham F. The oxygen paradox. Experiments on the effects of oxygen in human anoxia. Lancet 1951; 1 (6646): 77-81.

[10] Gerschman R, Gilbert D, Nye SW, Dwyer P, Fenn WO. Oxygen poisoning and $\mathrm{X}$-irradiation: A mechanism in common. Science 1954; 119: 236-9.

[11] DeLemos R, Wolfsdorf J, Nachman R, et al. Lung injury from oxygen in lambs: The role of artificial ventilation. Anesthesiology 1969; 30: 609-18.

[12] Auten RL, Davis JM. Oxygen toxicity and reactive oxygen species: The devil is in the details. Pediatr Res 2009; 66: 121-7.

[13] Pagano A, Barazzone-Argiroffo C. Alveolar cell death in hyperoxia-induced lung injury. Ann N Y Acad Sci 2003; 1010: 405-16.

[14] Wright CJ, Dennery PA. Manipulation of gene expression by oxygen: A primer from bedside to bench. Pediatr Res 2009; 66: 310.

[15] Jackson RM. Pulmonary oxygen toxicity. Chest 1985; 88: 900-5.

[16] Fialkow L, Wang Y, Downey GP. Reactive oxygen and nitrogen species as signaling molecules regulating neutrophil function. Free Radic Biol Med 2007; 42: 153-64.

[17] Godber BLJ, Doel JJ, Sapkota GP, et al. Reduction of nitrite to nitric oxide catalyzed by xanthine oxidoreductase. J Biol Chem 2000; 275: 7757-63.
[18] Li H, Samouilov A, Liu X, Zweier JL. Characterization of the magnitude and kinetics of xanthine oxidase-catalyzed nitrite reduction. Evaluation of its role in nitric oxide generation in anoxic tissues. J Biol Chem 2001; 276: 24482-9.

[19] Ryter SW, Alam J, Choi AM. Heme oxygenase-1/carbon monoxide: From basic science to therapeutic applications. Physiol Rev 2006; 86: 583-650.

[20] Hoetzel A, Dolinay T, Schmidt R, Choi AM, Ryter SW. Carbon monoxide in sepsis. Antioxid Redox Signal 2007; 9: 2013-26.

[21] Ghafourifar P, Richter C. Nitric oxide synthase activity in mitochondria. FEBS Lett 1997; 418: 291-6.

[22] Giulivi C, Poderoso JJ, Boveris A. Production of nitric oxide by mitochondria. J Biol Chem 1998; 273: 11038-43.

[23] Boveris A, Alvarez S, Navarro A. The role of mitochondrial nitric oxide synthase in inflammation and septic shock. Free Radic Biol Med 2002; 33: 1186-93.

[24] Cauwels A. Nitric oxide in shock. Kidney Int 2007; 72: 557-65.

[25] Hickey MJ, Sihota E, Amrani A, et al. Inducible nitric oxide synthase (iNOS) in endotoxemia: Chimeric mice reveal different cellular sources in various tissues. FASEB J 2002; 16: 1141-3.

[26] Bultinck J, Sips P, Vakaet L, Brouckaert P, Cauwels A. Systemic NO production during (septic) shock depends on parenchymal and not on hematopoietic cells: In vivo iNOS expression pattern in (septic) shock. FASEB J 2006; 20: E1619-E27.

[27] Hauser B, Bracht H, Matejovic M, Radermacher P, Venkatesh B. Nitric oxide synthase inhibition in sepsis? Lessons learned from large-animal studies. Anesth Analg 2005; 101: 488-98.

[28] Lopez A, Lorente JA, Steingrub J, et al. Multiple- center, randomized, placebo-controlled, double-blind study of the nitric oxide synthase inhibitor 546C88: effect on survival in patients with septic shock. Crit Care Med 2004; 32(1): 21-30.

[29] Wong HR, Carcillo JA, Burckart G, Shah N, Janosky JE. Increased serum nitrite and nitrate concentrations in children with the sepsis syndrome. Crit Care Med 1995; 23: 835-42.

[30] Wong HR, Carcillo JA, Burckart G, Kaplan SS. Nitric oxide production in critically ill patients. Arch Dis Child 1996; 74: 482-9.

[31] Doughty LA, Kaplan SS, Carcillo JA. Inflammatory cytokine and nitric oxide responses in pediatric sepsis and organ failure. Crit Care Med 1996; 24: 1137-43.

[32] Mitaka C, Hirata Y, Yokoyama K, et al. Relationships of circulating nitrite/nitrate levels to severity and multiple organ dysfunction syndrome in systemic inflammatory response syndrome. Shock 2003; 19: 305-9.

[33] Spack L, Havens PL, Griffith OW. Measurements of total plasma nitrite and nitrate in pediatric patients with the systemic inflammatory response syndrome. Crit Care Med 1997; 25: 1071-8.

[34] Lundberg JO, Weitzberg E. NO generation from nitrite and its role in vascular control. Arterioscler Thromb Vasc Biol 2005; 25: 91522 .

[35] Freeman B. Free radical chemistry of nitric oxide: looking at the dark side. Chest 1994; 105: 79S-84S.

[36] Beckman JS, Koppenol WH. Nitric oxide, superoxide, and peroxynitrite: The good, the bad, and ugly. Am J Physiol 1996; 271: C1424-C37.

[37] Roth E, Manhart N, Wessner B. Assessing the antioxidant status in critically ill patients. Curr Opin Clin Nutr Metab Care 2004; 7 : 161-8.

[38] Lemineur T, Deby-Dupont G, Preiser JC. Biomarkers of oxidative stress in critically ill patients: What should be measured, when and how? Curr Opin Clin Nutr Metab Care 2006; 9: 704-10.

[39] Berger MM, Chiolero RL. Antioxidant supplementation in sepsis and systemic inflammatory response syndrome. Crit Care Med 2007; 35: S584-S90.

[40] Tsukahara H. Biomarkers for oxidative stress: Clinical applications in pediatric medicine. Curr Med Chem 2007; 14: 339-51.

[41] El Mezayen R, El Gazzar M, Seeds MC, McCall CE, Dreskin SC, Nicolls MR. Endogenous signals released from necrotic cells augment inflammatory responses to bacterial endotoxin. Immunol Lett 2007; 111: 36-44.

[42] Calderwood SK, Mambula SS, Gray PJJ, Theriault JR. Extracellular heat shock proteins in cell signaling. FEBS Lett 2007; 581: 3689-94.

[43] Cuzzocrea S. Shock, inflammation, and PARP. Pharm Res 2005; 52: 72-82.

[44] Fink MP. Bench-to-bedside review: cytopathic hypoxia. Crit Care 2002; 6: 491-9. 
[45] Victor VM, Rocha M, De la Fuente M. Immune cells: free radicals and antioxidants in sepsis. Int Immunopharmacol 2004; 4: 327-47.

[46] Zingarelli B. Nuclear factor-kappaB. Crit Care Med 2005; 33: S414-S6.

[47] Hazelzet J, Driessen GJA, Abboud P, Wheeler DS, Shanley TP, Wong HR. Sepsis. In: Wheeler DS, Wong HR, Shanley TP, Eds. pediatric critical care medicine: basic science and clinical evidence. London, UK: Springer-Verlag London Limited 2007; pp. 1421-44.

[48] Zingarelli B, Sheehan M, Wong HR. Nuclear factor-kappaB as a therapeutic target in critical care medicine. Crit Care Med 2003; 31: S105-S11.

[49] Abraham E. Nuclear factor-kappaB and its role in sepsis-associated organ failure. J Infect Dis 2003; 187: S364-S9.

[50] Berger MM. Antioxidant micronutrients in major trauma and burns: evidence and practice. Nutr Clin Pract 2006; 21: 438-49.

[51] Heyland DK, Dhaliwal R, Suchner U, Berger MM. Antioxidant nutrients: a systematic review of trace elements and vitamins in the critically ill patient. Intensive Care Med 2005; 31: 327-37.

[52] Buonocore G, Groenendaal F. Anti-oxidant strategies. Sem Fetal Neonatal Med 2007; 12: 287-95.

[53] Marshall JC. Sepsis: rethinking the approach to clinical research. J Leukoc Biol 2008; 83: 471-82.
[54] Bernard GR, Vincent JL, Laterre PF, et al. Efficacy and safety of recombinant human activated protein $\mathrm{C}$ for severe sepsis. $\mathrm{N}$ Engl $\mathrm{J}$ Med 2001; 344(10): 699-709.

[55] Carcillo JA. Reducing the global burden of sepsis in infants and children: A clinical practice research agenda. Pediatr Crit Care Med 2005; 6: S157-S64.

[56] Seema, Kumar R, Mandal RN, et al. Serum TNF-alpha and free radical scavengers in neonatal septicemia. Indian J Pediatr 1999; 66: 511-6.

[57] Batra S, Kumar R, Seema, Kapoor AK, Ray G. Alterations in antioxidant status during neonatal sepsis. Ann Trop Paediatr 2000; 20: 27-33.

[58] Nemeth I, Boda D. Xanthine oxidase activity and blood glutathione redox ratio in infants and children with septic shock syndrome. Intensive Care Med 2001; 27: 216-21.

[59] Kapoor K, Basu S, Das BK, Bhatia BD. Lipid peroxidation and antioxidants in neonatal septicemia. J Trop Pediatr 2006; 52: 372-5.

[60] Cherian S, Jameson S, Rajarajeswari C, et al. Oxidative stress in sepsis in children. Indian J Med Res 2007; 125: 143-8.

(C) Derek S. Wheeler; Licensee Bentham Open.

This is an open access article licensed under the terms of the Creative Commons Attribution Non-Commercial License (http://creativecommons.org/licenses/by-nc/3.0/) which permits unrestricted, non-commercial use, distribution and reproduction in any medium, provided the work is properly cited. 